\title{
O combate de Rio das Antas (novembro de 1914): algumas considerações iniciais*
}

The battle of Rio das Antas (November 1914): some initial considerations

\author{
Márcia Janete Espig
}

Palavras-chave:

Guerra do Contestado

Rio das Antas

Microanálise

Keywords:

War of the Contestado

Rio das Antas

Microanalysis
Resumo: A colônia de Rio das Antas foi fundada pela Brazil Development \& Colonization Company (empresa de Colonização ligada à Brazil Railway Company) em terras das quais os moradores tradicionais haviam sido expulsos, tendo sido ocupada por imigrantes alemães e poloneses. Em 2 de novembro de 1914, no contexto da Guerra do Contestado, essa vila foi atacada pelo comandante geral dos rebeldes, Francisco Alonso, à frente de um piquete caboclo. Esse episódio, conhecido como combate de Rio das Antas, ficou marcado pela resistência dos colonos, pela morte de Alonso e pela fuga dos imigrantes da região. Neste artigo, pretendo discutir a fraca atenção dedicada a essa temática pela historiografia, trazendo algumas hipóteses de análise.

Abstract: The colony of Rio das Antas was founded by the Brazil Development \& Colonization Company (Colonization Company linked to the Brazil Railway Company) in lands from which the traditional inhabitants had been expelled and then occupied by German and Polish immigrants. In the context of the Contestado War, this village was attacked on November 2, 1914, by the general commander of the rebels, Francisco Alonso, head of a caboclo picket. This episode, known as the battle of Rio das Antas, was marked by the resistance of the settlers, the death of Alonso and the escape of the immigrants from that region. In this article, it is intended to discuss the poor attention dedicated to this topic by historiography, bringing some hypotheses of analysis.

Recebido em 09 de setembro de 2018. Aprovado em 21 de fevereiro de 2019.

\section{A guerra do Contestado: evolução historiográfica}

A Guerra do Contestado, ou Movimento do Contestado (1912-1916), foi um episódio muito importante da história do Brasil Republicano. Tratado por longa data como "história local" (catarinense ou paranaense; mas, sobretudo, catarinense) ou visto como uma "segunda Canudos" por leitores e pesquisadores desavisados, esse conflito vem ganhando progressiva visibilidade historiográfica, sendo relacionado a outros importantes temas de pesquisa, tais como o coronelismo, a transição monarquia/república, questão de terras, religiosidade popular, conflitos entre o tradicional e o inovador, dentre muitos outros.

Quando nos aproximamos desse objeto de estudo, em especial a partir de seus detalhes e singularidades, melhor se mostram seus contornos, suas especificidades e sua riqueza de interpretações. Se hoje temos uma imensa amplitude analítica a explorar, devemos ao trabalho de gerações de pesquisadores, que projetaram a temática muito além da história regional. Cabe aqui analisar, mesmo que brevemente, esse processo.

\footnotetext{
* O presente artigo apresenta uma reflexão ampliada sobre minha pesquisa de pós-doutoramento, recentemente iniciado na Universidade Federal de Santa Catarina, sob a supervisão do Dr. Paulo Pinheiro Machado.

** Professora associada da Universidade Federal de Pelotas (UFPel). Professora do Departamento de História e da Pós-Graduação em História da UFPel. Possui Licenciatura e Bacharelado em História pela Universidade Federal do Rio Grande do Sul (UFRGS). Realizou seu Mestrado em História e seu Doutorado em História pela mesma Universidade. E-mail: <marcia.espig@terra.com.br>.
} 
Uma primeira geração de interessados no assunto é representada pelos militares que lá estiveram na intenção de exterminar o movimento. Ao produzir relatos sobre a experiência na região, autores como Demerval Peixoto (publicações originais em 1916, 1918, 1920), Herculano d'Assumpção $(1917,1918)$ e J. O. Pinto Soares (1920, 1931), dentre outros, inauguraram certa linha de análise sobre a Guerra, seus participantes e a região em que ocorreu. Escrevendo em tom memorialístico, mas com intensões cívicas e críticas, esses autores foram definidos por Rogério Rosa Rodrigues como "historiadores de farda", visto que suas pretensões eram produzir obras históricas e definitivas sobre os acontecimentos (RODRIGUES, 2008, p. 106-108). Fonte de inúmeras informações, versões e mesmo distorções, tais obras tentavam alcançar - explicitamente em alguns casos - uma imortalização semelhante àquela alcançada pelo livro "Os Sertões", de Euclides da Cunha, que tratara, alguns anos antes, de tornar conhecido o Movimento de Canudos (1893-1897), ocorrido nos confins da Bahia e responsável por grande crise política na República que então se iniciava.

Anterior a esses trabalhos e portador de grande relevância, o "Relatório apresentado ao General de Divisão José Caetano de Faria, Ministro da Guerra (1916)" pelo General Fernando Setembrino de Carvalho, comandante das forças em operação no Contestado entre o mês de setembro de 1914 e maio de 1915, influenciou enormemente essa bibliografia militar, da qual podemos marcar aproximadamente os contornos cronológicos entre 1916 e os anos 30 do século XX. ${ }^{1}$

Saindo da esfera da produção militar, encontram-se no período imediatamente posterior alguns trabalhos de síntese histórica sobre o movimento, com destaque para Aujor Ávila da Luz (1952 em publicação original e 1999 em reedição) e Brasil Gerson (1955).

Os anos de 1960 a 1970 marcam o despertar de um novo interesse pelo Contestado, desta vez com perfil marcadamente acadêmico. Trabalhos como os de Oswaldo Cabral (1960, com reedição em 1979), Maria Isaura Pereira de Queiroz (1957) e Maurício Vinhas de Queiroz
(1966) assinalam essa inflexão, que se consolida com a obra de Duglas Teixeira Monteiro (1974 em primeira edição, 2011 em segunda edição). Dentre tais trabalhos, cabe destacar que a pesquisa de Vinhas de Queiroz solidificou-se como uma das principais obras informativas sobre o movimento, tendo se embasado em fontes jornalísticas, orais, militares, dentre outras. Mesmo que atualmente algumas informações ali apresentadas tenham sido desconstruídas por investigações pontuais, a explanação geral e estrutural sobre a constituição histórica e sociológica da região fazem desse um texto obrigatório para os que iniciam uma pesquisa. A investigação realizada por Monteiro (1974) se constitui em trabalho clássico sobre o conflito, traçando uma interpretação de fôlego acerca das relações de compadrio e os processos de desencantamento e reencantamento do mundo presentes no Contestado.

Curiosamente nenhum dos trabalhos mencionados acima foi produzido por historiador. Cabral era médico de formação, e Pereira de Queiroz, Vinhas de Queiroz e Monteiro eram sociólogos.

A produção historiográfica entre os anos 1980 e 2000 possui uma qualidade bastante variável. Conta com muitas obras de síntese sobre o movimento, alguns livros de reconstrução histórica (inovadores ou não) e variados trabalhos acadêmicos, tais como dissertações e teses. Sobre esses, tentarei traçar um panorama sintético e crítico. $^{2}$

Concomitantemente a textos que traçam sínteses sobre a Guerra do Contestado, tais como Antônio Pedro Tota (1983), Marli Auras (edição original em 1984 e reedição em 1995) e variados títulos de Nilson Thomé (1987, 1992), percebemos o crescimento de investigações pontuais, cujos trabalhos criaram problemas de pesquisa inovadores. As produções de Rosangela Cavallazzi (defendida em 1983 e publicada em 2003), que investigava a questão da terra, e de Ivone Gallo (1992), que se detinha sobre a questão do milenarismo, são exemplos do que afirmo. Outros importantes trabalhos também vieram a público no período, tais como o do brasilianista Todd Diacon 
(1991), de Célio Alves de Oliveira (1992) e de Delmir Valentini (1998). É perceptível um processo de crescimento e de qualificação das pesquisas realizadas sobre o Contestado, dessa vez com uma preponderância de estudiosos da área de história.

No início dos anos 2000 podemos falar em uma "nova historiografia" sobre o Contestado, formada por nomes como Paulo Pinheiro Machado, Márcia Janete Espig, Rogério Rosa Rodrigues, Tarcísio Mota Carvalho, Liz Andréa Dalfré, Alexandre Tomporoski, dentre outros. O trabalho mais importante desse período é o de Paulo Pinheiro Machado, cuja tese, que estuda em detalhe as lideranças do Contestado, passou a compor a bibliografia fundamental sobre o Movimento (MACHADO, 2004). Como mapeado em balanço realizado no simbólico ano de 2012,

Hoje, pode-se afirmar convictamente que o objeto de pesquisa Contestado sofreu um incremento numérico e qualitativo impressionante, se comparado a uma ou duas décadas atrás. Isso proporciona um desafio constante aos seus pesquisadores e às novas gerações de alunos. Esse padrão de qualidade acadêmica rende frutos, pois proporciona o avanço do conhecimento, que é o objetivo permanente de todo trabalho historiográfico (ESPIG et al., 2012, p. 9).

Os anos de 2012 a 2016 foram essenciais na constituição do que eu chamaria, na ausência de termo melhor, de "novíssima historiografia" sobre o Contestado. Com as comemorações alusivas ao centenário do Movimento, uma parcela dos pesquisadores citados acima organizou um evento em 2012, o "Simpósio Nacional do Centenário do Movimento Contestado: História, Memória, Sociedade e Cultura no Brasil Meridional, 19122012", que contou com três sessões (em Pelotas, Chapecó e Florianópolis). ${ }^{3}$ Considero que a visibilidade alcançada por esse e por outros eventos, bem como o processo contínuo de qualificação acadêmica e historiográfica que mencionei, levaram à formação dessa novíssima geração, constituída por nomes como de Viviani Poyer, Gabriel Kunrath, Cristina Dallanora, dentre muitíssimos outros. ${ }^{4}$
Recentemente Paulo Pinheiro Machado (2016, p. 1328) mapeou parte dessa riqueza historiográfica em um artigo, no qual menciona vários outros nomes não abordados aqui, mas igualmente relevantes, $\mathrm{e}$ que considera parte de uma "comunidade crescente de novos pesquisadores". Além da quantidade, chama a atenção a variedade de temáticas e problemas de pesquisa que vêm sendo enfrentados pelo grupo, formando uma volumosa e qualificada massa crítica.

A historiografia sobre o Contestado acompanhou avanços teórico-metodológicos e debates de diferentes áreas de conhecimento ligadas às ciências humanas, como pretendi demonstrar nessa breve exposição. As investigações mais recentes vêm propondo problemas de pesquisa específicos e com recortes precisos, muitas vezes de feição detalhista, característica que pode ser mais bem compreendida se pensarmos no amadurecimento que mapeei acima. Se hoje é possível realizar um estudo acerca de um episódio de talhe tão limitado quanto o Combate de Rio das Antas, devemos ao percurso dos estudos anteriores a compreensão de processos históricos fundamentais, tais como as estruturas vigentes na região, a evolução cultural do grupo, as lideranças, a expropriação capitalista, entre outros. Assim, o objeto de pesquisa que apresento posiciona-se em uma tendência atual dos estudos sobre o Contestado, e é tributário de uma maturidade não apenas pessoal, mas coletiva.

\section{Rio das Antas}

O combate de Rio das Antas ocorreu em 2 de novembro de 1914. Embora inexista, até agora, algum trabalho específico sobre esse episódio, ele nos serve para reflexão por tocar em várias questões importantes e sensíveis da história, não apenas do movimento, mas da região em que ocorreu.

A fundação da colônia de Rio das Antas está relacionada ao contexto de inserção capitalista no Vale do Rio do Peixe/SC. Entre 1908 e 1910 ocorreu a construção da Linha Sul da Estrada de Ferro São Paulo - Rio Grande (EFSPRG), que inaugurou a estação de Rio das Antas em maio de 1910. A Brazil Railway Company (BRC), empresa 
americana de capital multinacional, comprometerase com o governo federal a instalar colônias na região, aproveitando-se da concessão de terras recebida. Para realizar tal objetivo foi criada uma nova subsidiária da BRC, a Brazil Development \& Colonization Co. Essas empresas eram ligadas ao investidor norte-americano Percival Farquhar, cuja atuação em nosso país foi intensa durante a Primeira República. $^{5}$
Ao final de 1910 já se realizavam estudos no Vale do Rio do Peixe, onde se esperava medir 100 lotes ao redor das estações para instalar colonos vindos da Europa. Tais núcleos foram de fato implantados a partir de 1911 em Rio das Antas, Herval, Rio Capinzal, Rio do Peixe e Rio Uruguay, embora não nas dimensões inicialmente desejadas (ESPIG, 2011, p. 356). ${ }^{6}$ A seguir (Figura 1), mapa da BRC que localiza Rio das Antas geograficamente e apresenta os lotes à venda.

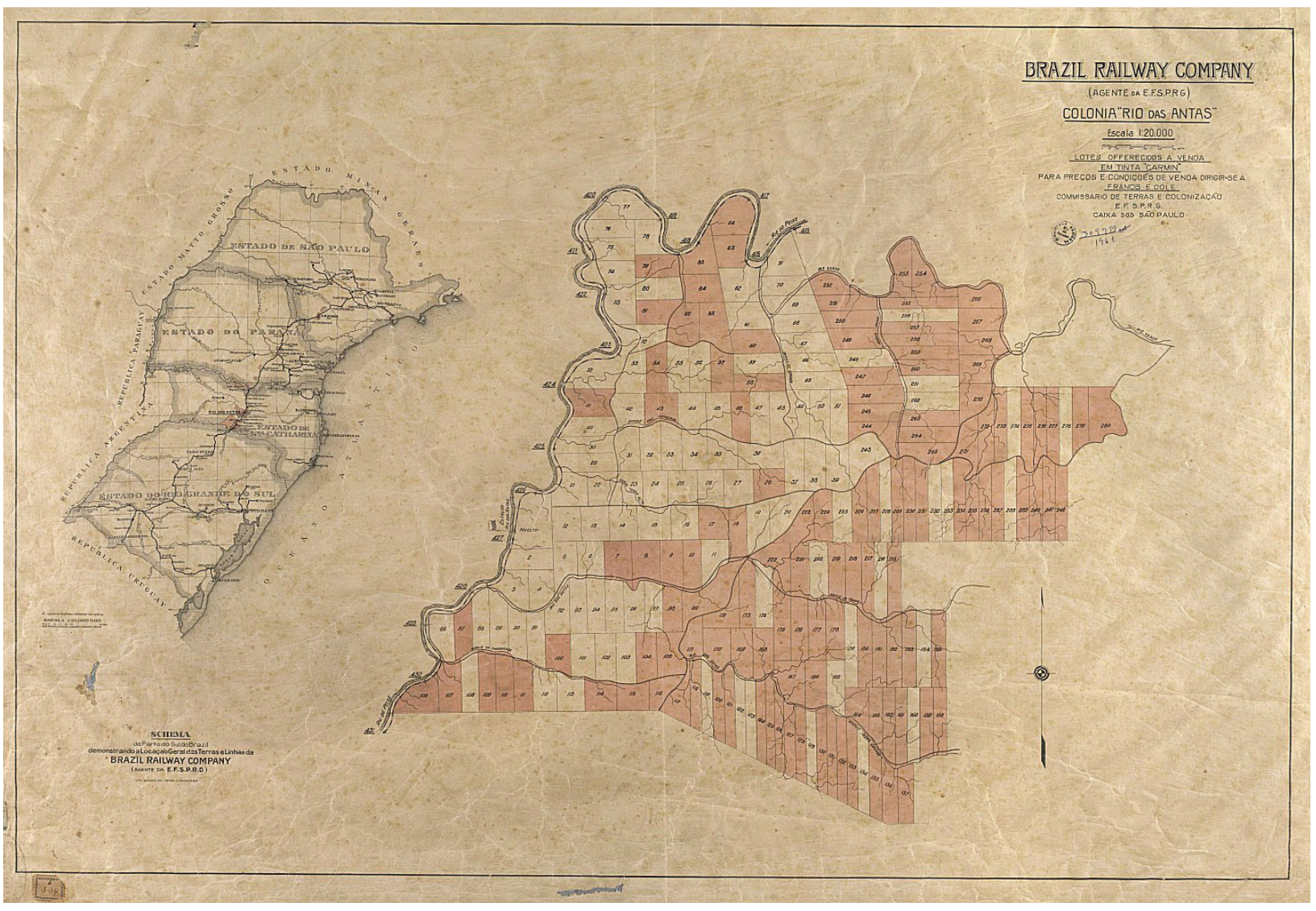

Figura 1: Mapa da Colônia Rio das Antas.

Fonte: Brazil Railway Company.([s.d.]).

As colônias do Vale do Rio do Peixe, contudo, não obtiveram sucesso.

Ainda em 1911, ao Sul do eixo Porto União-Mafra, agora no Alto Vale do Rio do Peixe, a companhia ferroviária fez uma das primeiras tentativas de colonização das terras marginais aos trilhos, com a instalação do pioneiro núcleo de famílias alemãs imigrantes na Estação de Rio das Antas, e na Colônia Rio do Peixe (hoje Piratuba). O plano de colonização foi interrompido em 1914 por causa da Guerra do Contestado, sendo reiniciado em 1918 (THOMÉ, 2007, p. 78).

Em 1915 havia poucos colonos estabelecidos na região, sendo o conflito com os "fanáticos" parcialmente responsabilizado por essa situação. A situação mais dramática, não restam dúvidas, foi justamente a de Rio das Antas, devido ao ataque ocorrido. Naquele local, a empresa norte-americana 
havia expulsado de suas terras um grande número de posseiros, tendo loteado e vendido a terra a imigrantes poloneses e alemães (VINHAS DE QUEIROZ, 1966, p. 231; MONTEIRO, 2011, p. 60).

O momento do ataque (novembro de 1914) marcava um período especialmente delicado para os rebeldes do Contestado. Como bem apontou Machado, entre julho e novembro de 1914 o movimento alcançara grande expansão, em uma "ofensiva generalizada" (2004, p. 261-ss) que resultou em grande volume de mortes, dentre as quais figura o emblemático assassinato do Capitão Matos Costa. Em setembro desse mesmo ano, o comando da Expedição Militar no Contestado foi passado ao General Fernando Setembrino de Carvalho, que contou com um volume de recursos - financeiros e humanos - imensamente superior às Expedições Militares anteriores. Quando, um mês antes do ataque, o comandante rebelde mandou avisar aos colonos de Rio das Antas que esses deveriam se retirar da localidade sob pena de um assalto impiedoso, o movimento já entrava em inflexão.

Francisco Alonso de Souza, o Chico Alonso, era posseiro no vale do Timbó e foi guindado ao cargo de comandante geral do movimento com a decadência das chefias religiosas, notadamente de Maria Rosa, por volta de junho de 1914 (MACHADO, 2004, p. 248). ${ }^{7}$ A despeito de diferenças internas entre as variadas lideranças, os meses a partir daí foram de expansão, com ataques às vilas de Canoinhas, Itaiópolis, Papanduva, Vila Nova do Timbó, Curitibanos e a tentativa (malsucedida) de tomar a cidade de Lages. Esse foi o momento de maior expansão geográfica do movimento, com inúmeros ataques bem-sucedidos. Ressalto, ainda, a ofensiva contra as estações de Calmon e São João dos Pobres, da EFSPRG, bem como de uma madeireira da Lumber, ações nas quais a violência potencializou-se e provocou o pavor da população. ${ }^{8}$

Em vários ataques os rebeldes adotaram a estratégia de mandar avisos. No caso de Curitibanos, por exemplo, essa tática permitiu a tomada da Vila sem maiores conflitos, e nenhuma pessoa morreu na invasão ou durante sua ocupação pelo grupo chefiado por Chico Ventura (MACHADO, 2008, p. 83). Além de proporcionar menor resistência, tal tática também acabava por mitigar o número de mortes. Quando o mesmo recado foi passado aos habitantes da pequena Rio das Antas, não se esperava resistência. Ali, alguns dos homens que compunham o piquete de Alonso tinham pendências a resolver, pois eram ex-posseiros desalojados (talvez com a esperança de retomar a posse das terras). A expectativa pela fuga dos colonos não se confirmou, e esses organizaram a defesa da localidade mesmo sem o apoio militar. A dura resposta ao ataque resultou em baixas para os colonos e para os sertanejos, que perderam seu líder e mais alguns homens do piquete. Os sobreviventes, ao verem o chefe morto, safaramse. Entre eles estava o derradeiro comandante do movimento, Adeodato (FELLIPPE, 1995, p. 175). Com medo de uma possível represália, os colonos retiraram-se da região. Teriam, segundo Vinhas de Queiroz, vendido seus pertences às praças do Exército e resolvido se mudar para São Paulo (1966, p. 232), ou teriam sido removidos pela Companhia Colonizadora para Cachoeira, no estado do Paraná, e para Faxina, em São Paulo, onde receberam novas terras (GAERTNER, 1974, p. 181).

O local da Batalha de Rio das Antas foi objeto de um levantamento de cultura material, realizado pelo arqueólogo Jaisson Teixeira Lino. Inserindo esse espaço em uma reflexão acerca da "arqueologia dos conflitos" e da "arqueologia dos campos de batalha", esse autor menciona a necessidade de os campos de batalha serem vistos "[...] em sua dupla existência, como local onde se desenrolaram conflitos bélicos, e como lugar no presente que possui depósitos arqueológicos e que foi reapropriado pelas populações atuais como ponto de evocação de memórias" (LINO, 2014, p. 134). 


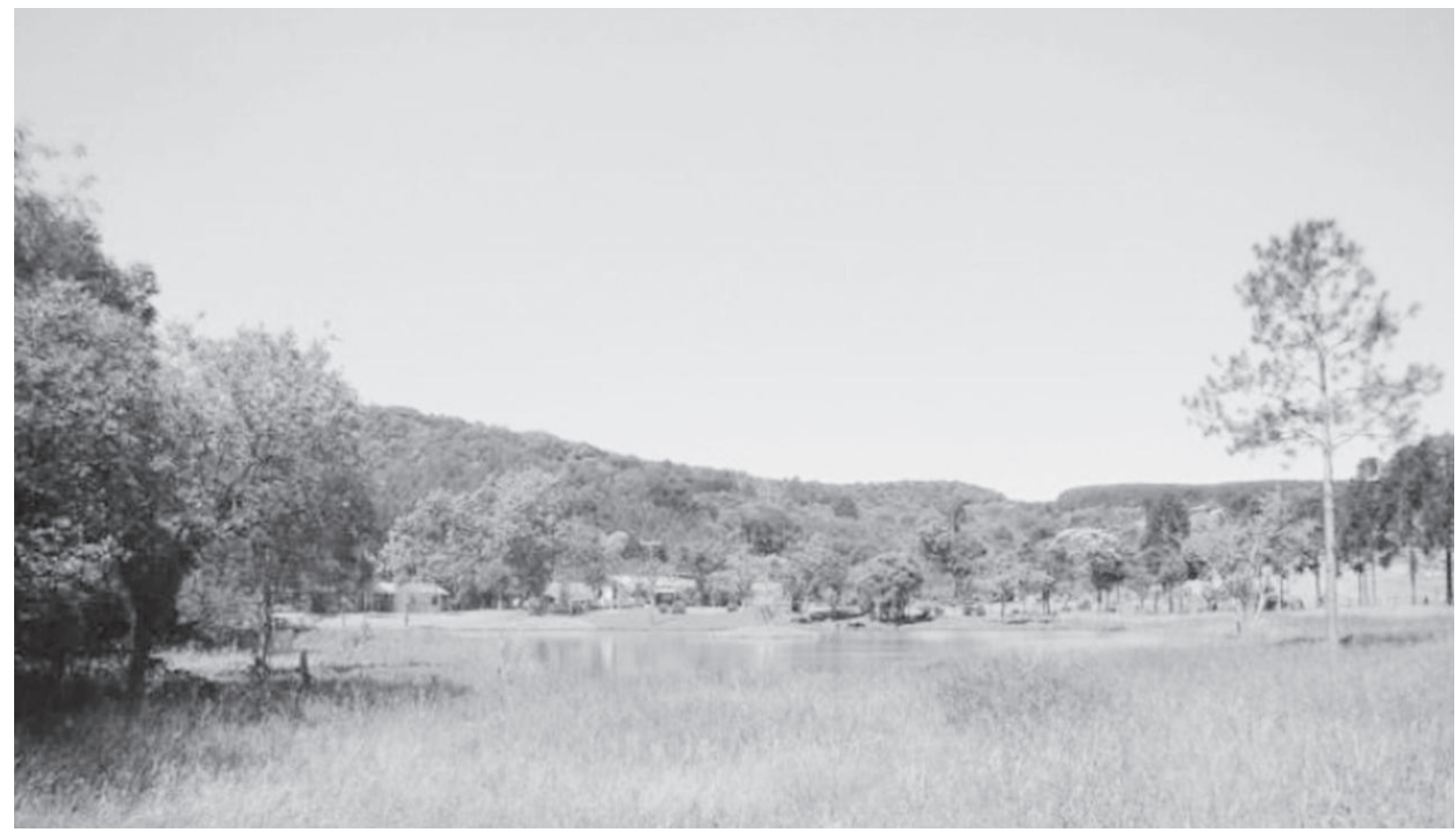

Figura 2 - Local da Batalha de Rio das Antas, Rio das Antas. Fonte: Lino (2014, p. 135).

No transcorrer da Guerra do Contestado, vários foram os combates, as batalhas ou os ataques que se tornaram célebres. Menciona-se, por exemplo, o combate de Taquaruçu, o ataque à vila de Curitibanos, o cerco a Lages ou o combate de Santa Maria, de tão trágico desfecho. Percebe-se que cada um desses episódios, inserido em um microcontexto histórico específico, desempenhou papel importante no desenvolvimento do movimento. Contudo, raras são as pesquisas que investigam a fundo tais momentos de conflito e ruptura.

Certamente a batalha mais conhecida da Guerra do Contestado é a Batalha do Irani. Considerada o marco inicial do conflito, em 22 de outubro de 1912, sua relevância não escapou aos pesquisadores, sendo sempre mencionada em trabalhos de síntese ou resumos sobre o tema. Sobre ela temos trabalhos específicos, como o de Celso Vianna (2002) que, a partir de uma perspectiva antropológica, busca compreender os testemunhos e as reminiscências dos agentes históricos envolvidos. Já a pesquisa de Celso Martins (2007) realiza uma narrativa cronológica dos eventos, baseando-se, sobretudo, no processo instaurado em $1913 .{ }^{9}$
$\mathrm{O}$ ataque a Curitibanos foi objeto de um artigo de Machado (2008). Nesse, o autor demonstra como a investigação detalhada sobre um conflito localizado pode nos ajudar a entender aspectos importantes da organização do movimento, seu funcionamento, a relação entre lideranças e, sobretudo, a vigência e o respeito a antigos laços de parentesco e compadrio entre "pelados" e "peludos" (MACHADO, 2008, p. 88).

A possibilidade de estudo de ataques, batalhas, cercos e combates específicos no interior de um conflito complexo como a Guerra do Contestado se apresenta como um campo promissor e extremamente relevante para futuros pesquisadores. Alguns desses episódios contam com fontes pouco exploradas, tais como processos judiciais ou militares, além da abordagem da imprensa da época e de relatórios oficiais. Como demonstrei, progressivamente a historiografia sobre esse movimento evoluiu de trabalhos de síntese estrutural (absolutamente necessários, diga-se de passagem), para pesquisas com recortes específicos e talhe limitado. Alavancado pela variedade teórica atualmente existente, bem como pelo arcabouço 
de conhecimento alcançado coletivamente através das gerações de pesquisadores anteriores, esse crescimento historiográfico somente contribui para a excelência das investigações mais recentes.

A historiografia ainda se ressente da falta de um estudo que aborde em detalhes o combate de Rio das Antas. Trabalhos de síntese histórica sobre o Contestado, tais como os textos de Luz (1999), Tota (1983-) ou Auras (1995), apenas mencionam a ocorrência do combate de Rio das Antas, sem agregar maiores informações. Maurício Vinhas de Queiroz utiliza exatamente 40 linhas de seu clássico livro para tratar do episódio em questão (1966, p. 231-232), o que faz dele o autor que mais dedicou espaço ao Combate de Rio das Antas até o presente momento, em uma narrativa que menciona as ameaças de Chico Alonso e alguns detalhes do ataque. Pesquisas mais recentes, que possuem problemas de pesquisa específicos, abordam o combate de Rio das Antas ou a morte de Chico Alonso de forma incidental, por exemplo, Machado (2004, p. 276), Espig (2011, p. 357), Tomporoski (2012, p. 79-80) ou Poyer (2016, p. 4), contribuindo para uma melhor reconstrução do contexto histórico mas não para o debate sobre esse objeto de pesquisa propriamente dito. ${ }^{10}$

Como proposta, acredito na importância de se ampliar a narrativa histórica e factual sobre o ocorrido, além de amplificar a interpretação e a análise desse acontecimento. A compreensão histórica da Batalha de Rio das Antas se posiciona na confluência de debates mais amplos, podendo servir para iluminar questões relevantes sobre o Contestado e sobre a história da região. Questões como a relação entre os imigrantes e a Companhia Colonizadora, entre os imigrantes e os caboclos (sobretudo os posseiros expulsos da área que aqueles vieram a ocupar), a relação entre a batalha e o desenvolvimento regional, entre outras, são aspectos pertinentes e ainda em busca de respostas. Por meio da variação da escala de análise, pretendo produzir uma narrativa e uma interpretação condizentes com o micro e o macrocontexto em que se desenvolveu aquele episódio. Buscando indícios, vestígios e detalhes, cotejando fontes documentais dos mais diversos tipos, almeja-se alcançar a ação dos diferentes agentes históricos, bem como a relação de forças existente entre eles e seus desdobramentos para o Movimento do Contestado e para a história regional.

\section{Aspectos teórico-metodológicos da investigação}

Por muito tempo a historiografia que estudava eventos, tais como batalhas, combates e ataques, parecia restrita ao enfoque de uma história política, tradicional ou militar. ${ }^{11}$ A variedade atual de acepções teórico metodológicas aponta para inúmeras possibilidades interpretativas ou de tratamento das fontes, sendo uma das mais pertinentes a metodologia micro-histórica. Essa, somada a uma aproximação da história social, pode proporcionar uma melhor abordagem da temática e das fontes documentais.

Uma investigação não se justifica apenas pela curiosidade do pesquisador sobre o tema, mas pela virtualidade analítica proporcionada pelo objeto escolhido. Esse é o caso do combate de Rio das Antas, já que tal episódio agrega em si (como demonstrei) o debate sobre variados aspectos do movimento do Contestado e da história regional, possibilitando somar conhecimento.

O combate de Rio das Antas, enquanto tema de pesquisa, foi, tradicionalmente, relegado à categoria de "nota de rodapé" da história do Contestado. Tratado brevemente, em um ou dois parágrafos, ou meramente como um complemento de informação trazido ao pé da página, sua relevância poderia ser discutida por uma história com pretensões globais. Pela variação da escala de análise; contudo, o episódio apresenta-se como um rico entrelaçar de personagens e situações consistentes para um debate sobre a Guerra do Contestado. $\mathrm{O}$ alerta quanto às "notas de rodapé da história" vem de Carlo Ginzburg. Seu conhecido livro "O Queijo e os Vermes" demonstra soberbamente que os temas de pesquisa micro podem alcançar grande relevância e escapar da sina de permanecer em pé de página (1987). Em suas palavras,

Reduzir a escala de observação queria dizer transformar num livro aquilo que, para outro estudioso, poderia ter 
sido uma simples nota de rodapé numa hipotética monografia sobre a Reforma protestante no Friul. (GINZBURG, 2007, p. 264).

Ao reduzir a escala de observação, operamos um procedimento metodológico para atingir a riqueza desse tema, que de outra forma poderia permanecer inalcançável. A observação microhistórica, nesse sentido,

[...] afirma em princípio que a escolha de uma escala particular de observação produz efeitos de conhecimento, e pode ser posta a serviço de estratégias de conhecimento. Variar a objetiva não significa apenas aumentar (ou diminuir) o tamanho do objeto no visor, significa modificar sua forma e sua trama. (REVEL, 1998, p. 20).

Ao modificar a forma e a trama de um objeto de pesquisa, ambiciona-se revelar fatores que de outra maneira não seriam visíveis. Ressalte-se a característica experimental do método (LEVI, 1992, p. 139), que deve ser conjugado ao uso intensivo do material documental e à profundidade analítica da interpretação. Espera-se, com tais procedimentos, que os fenômenos assumam significados inovadores, alcançando uma "[...] reconstituição do vivido impensável noutros tipos de historiografia [...]" (GINZBURG, 1991, p. 177-178).

A valorização do sujeito histórico, trazido pela micro-história, tenta perceber como as transformações ocorrem ao nível dos comportamentos concretos e individuais (seja do indivíduo uno ou coletivo). Com isso, seria possível dar visibilidade à multiplicidade de itinerários de indivíduos e grupos, às incertezas, às estratégias relacionais utilizadas, às formas de agregação e desagregação do grupo, atingindo espaços inovadores, complexificando e enriquecendo o material do historiador. Colocase em jogo não apenas o acontecido, mas também as possibilidades de destino dos atores, ou a reconstituição de um "espaço dos possíveis", conforme Revel (1998, p. 26), aspecto muito importante ao repensarmos as destinações dos imigrantes ao abandonar Rio das Antas.
Variação da escala de análise, flexibilidade metodológica, amplitude analítica e uso intensivo de fontes: tais princípios, oriundos da microhistória, são fundamentais para pensar a atual temática. A busca de evidências documentais inéditas será conjugada ao olhar detalhado sobre fontes já utilizadas por pesquisadores anteriores, tais como jornais e memórias militares. Portanto, a coleta documental se pretende ampla e baseada em princípios qualitativos.

Por hipótese, acredito que o conhecimento presente na historiografia sobre a Batalha de Rio das Antas baseia-se, sobretudo, em dois tipos de fontes: os periódicos e as memórias militares. Portanto, como uma primeira etapa de pesquisa, cabe uma varredura detalhada sobre ambas, através de coleta via acervos on-line e em bibliotecas. Após essa etapa metodológica, de revisitar fontes já estudadas no intuito de entender a composição das atuais versões sobre o episódio, partirei para a coleta de fontes inéditas, que poderão ampliar a narração e a interpretação sobre essa batalha. Processos, judiciais ou militares, e documentações oficiais são alguns dos materiais de pesquisa que serão buscados. ${ }^{12}$

A análise de fontes será minuciosa, detalhista, ou "infernal", no dizer de E. P. Thompson (1981, p. 36). Ao colocar o documento de cabeça para baixo e sacudi-lo, como propõe o autor, percebemos a necessidade de extrair dali informações e análises, já que o sentido de uma fonte não se dá por si: "A evidência histórica existe em sua forma primária, não para revelar seu próprio significado, mas para ser interrogada por mentes treinadas numa disciplina de desconfiança atenta" (THOMPSON, 1981, p. 38). A interpretação dos documentos vai além de uma mera leitura, constituindo um complexo trabalho de desmistificação, no qual o vestígio deve ser visto como um produto de uma época, de um indivíduo ou grupo. Como nos recorda Le Goff (1996, p. 547),

O documento não é inócuo. É, antes de mais nada, o resultado de uma montagem consciente ou inconsciente da história, da época, da sociedade que o produziram, mas também das épocas sucessivas durante as quais continuou a viver, talvez esquecido, durante as quais continuou a ser manipulado, ainda que pelo silêncio. 
Uma leitura metodologicamente orientada das fontes, buscando cotejar sua origem, produção e conservação, pode nos levar a perguntas pertinentes e respostas consistentes. Para conhecermos mais sobre o combate de Rio das Antas, buscaremos o sentido mais profundo da documentação existente, sob uma perspectiva qualitativa de análise. Compreender melhor as ações dos personagens históricos envolvidos, tais como os posseiros expulsos dos lotes de Rio das Antas, os imigrantes lá assentados e mesmo a ação - e a inação - dos representantes do Exército Nacional no episódio pode ter como filtro a compreensão das relações de força presentes naquela sociedade no contexto estudado. Lembrando Ginzburg (2002, p. 43),

[...] ao avaliar as provas, os historiadores deveriam recordar que todo ponto de vista sobre a realidade, além de ser intrinsecamente seletivo e parcial, depende das relações de força que condicionam, por meio da possibilidade de acesso à documentação, a imagem total que uma sociedade deixa de si. Para "escovar a história ao contrário" [...] como Walter Benjamim exortava a fazer, é preciso ler os testemunhos às avessas, contra as intenções de quem os produziu. Só dessa maneira será possível levar em conta tanto as relações de força quanto aquilo que é irredutível a elas.

\section{Conclusões}

Por se tratar de uma investigação incipiente, nesse momento do trabalho as conclusões se confundem com as hipóteses de pesquisa. Uma delas se refere ao papel até aqui pouco significativo da historiografia para um conhecimento mais profundo sobre o Combate de Rio das Antas, bem como seu atrelamento ao uso de dois tipos de fontes históricas preponderantemente, a saber, os periódicos e as memórias militares. Ao se comprovar tais hipóteses, propõe-se para superação de tais problemas a pesquisa de documentações inéditas, mediadas por referenciais teórico metodológicos vinculados à micro-história. Dessa forma, a partir de vestígios, indícios e sinais que vão além dos já utilizados, desejo aprofundar o estudo ao ponto de propor interpretações inovadoras para o episódio, agregando conhecimento sobre o fato em si, seus personagens e os processos históricos que dali decorreram.

\section{Notas}

1 Embora até hoje tenhamos obras de pesquisadores ligados ao pensamento militar, as mais atuais parecem apenas repetir informações e preconceitos na tentativa de defender a atuação do Exército Nacional no episódio.

2 Por opção deixarei de fora desse debate algumas obras que considero de fraca relevância acadêmica, em geral produzidas por diletantes e que pouco fazem além de reproduzir estereótipos e narrativas desabonadoras sobre os rebeldes do Contestado. Várias foram publicadas no período citado, ou mesmo posteriormente.

$3 \mathrm{O}$ evento contou, até aqui, com cinco edições, e a última ocorreu em 2018, em Irati, no Paraná. Os eventos proporcionaram a publicação de vários livros e revistas acadêmicas de produção coletiva.

4 A criação do GIMC (Grupo de Investigações sobre o Movimento do Contestado), grupo de pesquisa certificado pelo CNPq, no ano de 2011, também foi um importante passo no processo evolutivo que apresento.

5 Sobre o assunto, vide SINGER, 1985, p. 377-389; e ESPIG, 2011, p. 139-ss.

60 município de Rio das Antas, localizado na Região do Alto Vale do Rio do Peixe, em Santa Catarina, está situado a 810 metros de altitude, nas seguintes coordenadas geográficas: Latitude: $26^{\circ} 31^{\prime} 35^{\prime \prime}$ Sul, Longitude: $50^{\circ} 13^{\prime}$ $45^{\prime}$. Possui atualmente $317,2 \mathrm{~km}^{2}$ e cerca de 6.200 habitantes (BRASIL, [s. d.]). Rio das Antas foi criado como distrito do município de Campos Novos em 18 de novembro de 1914, através da lei municipal $\mathrm{n}^{\circ} 208$. Em divisões territoriais datadas de 31 de dezembro de 1936 e 31 de dezembro de 1937, Rio das Antas passou a pertencer ao município de Caçador. Assim permaneceu até sua elevação à categoria de município, através da lei estadual ${ }^{\circ} 348$, de 21 de junho de 1958 (IBGE, 1948, p. 3).

7 A melhor investigação sobre esse processo interno de troca de lideranças religiosas pelas "de briga" é o trabalho de Machado (2004), que investigou a fundo as diferentes lideranças do Movimento em suas diversas fases.

8 Sobre os ataques e o assassinato do Capitão Matos Costa, ver Espig (2011, p. 234-ss).

9 Ressalto, ainda, a existência de pesquisa de mestrado em desenvolvimento sobre a Batalha do Irani, realizada pelo historiador Gabriel Kunrath sob minha orientação.

10 Esse levantamento pretende apenas mapear a existência de uma lacuna historiográfica, não emitindo 
juízo de valor sobre ela. A criação de problemas de pesquisa relevantes no trabalho historiográfico é tarefa complexa, sobre a qual incidem inúmeras variáveis objetivas e subjetivas, que não pretendo analisar aqui.

11 Essa questão não escapou ao grande historiador Georges Duby que, ao elaborar sua pesquisa sobre uma batalha específica, a Batalha de Bouvines, sentiu a necessidade de explicar porque aceitara o convite para escrever sobre "Um acontecimento. Pontual. Retumbante" (DUBY, 1993, p. 9).

12 Alguns dos locais de pesquisa que serão percorridos são o Museu do Judiciário, no Tribunal de Justiça de Santa Catarina, o Fórum de Campos Novos (antiga sede de Rio das Antas), o Arquivo Público do Estado de Santa Catarina (APESC) e o Arquivo do Exército, no Rio de Janeiro. Outros locais na capital carioca, como o Arquivo Nacional, Biblioteca Nacional, Instituto HistóricoGeográfico e Centro de Pesquisa e Documentação de História Contemporânea do Brasil - CPDOC, também serão visitados.

\section{Referências}

ASSUMPÇÃO, Herculano Teixeira d'. A campanha do Contestado (as operações da Columna do Sul). Belo Horizonte: Imprensa Oficial do Estado de Minas Gerais, 1917. v. 1.

ASSUMPÇÃO, Herculano Teixeira d'. A campanha do Contestado (as operações da Columna do Sul). Belo Horizonte: Imprensa Oficial do Estado de Minas Gerais, 1918. v. 2.

AURAS, Marli. Guerra do Contestado: a organização da irmandade cabocla. 2. ed. Florianópolis: Editora da UFSC, 1995.

BRASIL. Ministério do Desenvolvimento Agrário. Perfil Territorial. Alto Vale do Rio do Peixe SC. ([s. d.]). Disponível em: http://sit.mda.gov. br/download/caderno/caderno_territorial_155_ Alto\%20Vale\%20do\%20Rio\%20do\%20Peixe\%20 -\%20SC.pdf. Acesso em: 18 fev. 2019.

BRAZIL RAILWAY COMPANY. ([s. d.]). Disponível em: http://www.estacoesferroviarias. com.br/pr-tronco/riodasantas.htm. Acesso em: 18 fev. 2019.

BURKE, Peter (Org.). A escrita da história: novas perspectivas. São Paulo: Unesp, 1992.
CABRAL, Oswaldo Rodrigues. A Campanha do Contestado. 2. ed. Florianópolis: Editora Lunardelli, 1979 .

CARVALHO, Fernando Setembrino de. Relatório apresentado ao General de Divisão José Caetano de Faria, Ministro da Guerra. Rio de Janeiro: Imprensa Militar, 1916.

CARVALHO, Tarcísio Motta de. "Nós não tem direito": costume e direito à terra no Contestado (1912/1916). 2002. 214 f. Dissertação (Mestrado em História) - Programa de Pós-Graduação em História, Universidade Federal Fluminense, Niterói, 2002.

CAVALLAZZI, Rosângela Lunardelli. Contestado: espaço do camponês, tempo da propriedade privada. Florianópolis: Fundação Boiteux, 2003.

CIDADES do Brasil. Município de Rio das Antas. 1 jan. 2018. Disponível em: https://www.cidadebrasil.com.br/municipio-rio-das-antas.html. Acesso em 18 fev. 2019.

DALFRÉ, Liz Andréa. Outras narrativas da nacionalidade: o Movimento do Contestado. 2004. 154 f. Dissertação (Mestrado em História) - Programa de Pós-Graduação em História, Universidade Federal do Paraná, Curitiba, 2004.

DIACON, Todd A. Millenarian vision, capitalist reality: Brazil's Contestado rebellion, 1912-1916. Durham: Duke University Press, 1991.

DUBY, George. O domingo de Bouvines: 27 de julho de 1214. Rio de Janeiro: Paz e Terra, 1993.

ESPIG, Márcia Janete. Personagens do Contestado: os turmeiros da Estrada de Ferro São Paulo - Rio Grande (1908-1915). Pelotas: Editora Universitária/ UFPel, 2011.

ESPIG, Márcia Janete et al. Aspectos históricos sobre o centenário do Contestado. Revista Esboços, v. 19, n. 28, p. 1- 12, dez. 2012.

FELIPPE, Euclides José. $\mathbf{O}$ último jagunço. Folclore na história do Contestado. Curitibanos: Universidade do Contestado, 1995. 
GAERTNER, Carlos. Um cinqüentenário em Rio das Antas. Blumenau em Cadernos, Blumenau, tomo XV, n. 10, p. 180-185, out. 1974.

GALLO, Ivone Cecília d'Ávila. O Contestado: o sonho do milênio igualitário. Campinas: Ed. da Unicamp, 1999.

GERSON, Brasil. Pequena história dos fanáticos do Contestado. Rio de Janeiro: MEC, 1955.

GIESBRECHT, Ralph Mennucci. Rio das Antas (antiga Campos Novos) Município de Rio das Antas, SC. Estações Ferroviárias do Brasil, 3 out. 2018. Disponível em: http://www.estacoesferroviarias. com.br/pr-tronco/riodasantas.htm Acesso em: 18 fev. 2019.

GINZBURG, Carlo. O queijo e os vermes: o cotidiano e as idéias de um moleiro perseguido pela inquisição. São Paulo: Companhia das Letras, 1987.

GINZBURG, Carlo. A micro-história e outros ensaios. Lisboa: Difel, 1991.

GINZBURG, Carlo. Relações de força - história, retórica, prova. São Paulo: Companhia das Letras, 2002.

GINZBURG, Carlo. O fio e os rastros: verdadeiro, falso, fictício. São Paulo: Companhia das Letras, 2007.

INSTITUTO BRASILEIRO DE GEOGRAFIA E ESTATÍSTICA. Rio das Antas - Santa Catarina/ SC. [s. d.]. Disponível em: https://biblioteca.ibge. gov.br/visualizacao/dtbs/santacatarina/riodasantas. pdf Acesso em: 18 fev. 2019.

INSTITUTO BRASILEIRO DE GEOGRAFIA E ESTATÍSTICA. Sinopse Estatística do Município de Campos Novos. Estado de Santa Catarina. Rio de Janeiro: Serviço gráfico do IBGE, 1948.

LEVI, Giovanni. Sobre a micro-história. BURKE, Peter (Org.). A escrita da história: novas perspectivas. São Paulo: Unesp, 1992. p. 133-162.

LE GOFF, Jacques. História e memória. 4. ed. Campinas: UNICAMP, 1996.
LINO, Jaisson Teixeira. A guerra do Contestado no Sul do Brasil: Um Enfoque Arqueológico. In: LEAL, Elisabete; PAIVA, Odair da Cruz (Org.). Patrimônio e História. 1. ed. Londrina: Editora Unifil, 2014. p. 125-138.

LUZ, Aujor Ávila da. Os fanáticos: crimes e aberrações da religiosidade dos nossos caboclos (contribuição para o estudo da antropossociologia criminal e da história do movimento dos fanáticos em Santa Catarina). Florianópolis: Editora da UFSC, 1999.

MACHADO, Paulo Pinheiro. Lideranças do Contestado: a formação e a atuação das chefias caboclas (1912-1916). Campinas: Ed. da Unicamp, 2004.

MACHADO, Paulo Pinheiro. A invasão de Curitibanos: retratos de uma "guerra fraterna"? In: ESPIG, Márcia; MACHADO, Paulo (Org.). A Guerra Santa revisitada: novos estudos sobre o movimento do Contestado. Florianópolis: Ed. da UFSC, 2008. p. 73-89.

MACHADO, Paulo Pinheiro. Contestado: o centenário da Guerra e o conflito sem fim. In: PRIORI, Ângelo; GRUNER, Clóvis (Org.). Contestado: 100 anos de uma guerra sem fim: movimentos e conflitos sociais no sul do Brasil: estudos sobre Santa Catarina e Paraná (séculos XIX e XX). Curitiba: ANPUH, 2016. p. 13-28.

MARTINS, Celso. O mato do tigre e o campo do gato: José Fabrício das Neves e o Combate do Irani. Florianópolis: Insular, 2007.

MONTEIRO, Duglas Teixeira. Os errantes do novo século: um estudo sobre o surto milenarista do Contestado. 2. ed. São Paulo: Edusp, 2011.

OLIVEIRA, Célio Alves de. A construção e a permanência do mito de João Maria de Jesus na região do Contestado, Santa Catarina. 1992. 187 f. Dissertação (Mestrado em Antropologia Social) - Programa de Pós-Graduação em Antropologia, Universidade Federal do Rio Grande do Sul, Porto Alegre, 1992. 
PEIXOTO, Demerval. Campanha do Contestado. Curitiba: Fundação Cultural, 1995a.

PEIXOTO, Demerval. Campanha do Contestado. Curitiba: Fundação Cultural, 1995b.

PEIXOTO, Demerval. Campanha do Contestado. Curitiba: Fundação Cultural, 1995c.

PEREIRA DE QUEIROZ, Maria Isaura. La "Guerre Sainte" au Brésil: Le mouvement messianique du "Contestado". São Paulo: Universidade de São Paulo, 1957.

POYER, Viviani. Fronteiras de uma guerra: diplomacia e relações internacionais no movimento do Contestado. In: ENCONTRO ESTADUAL DE HISTÓRIA DA ANPUH - HISTÓRIA E MOVIMENTOS SOCIAIS, 16., 8-10 jun. 2016, Chapecó. Anais... Chapecó: UFFS, 2016. p. 1-13.

REVEL, Jacques (Org.). Jogos de escala: a experiência da micro-análise. Rio de Janeiro: Fundação Getúlio Vargas, 1998.

RODRIGUES, Rogério Rosa. Os sertões catarinenses: embates e conflitos envolvendo a atuação militar na Guerra do Contestado. 2001. 115 f. Dissertação (Mestrado em História) - Programa de Pós-Graduação em História, Universidade Federal de Santa Catarina, Florianópolis 2001.

RODRIGUES, Rogério Rosa. Veredas de um grande sertão: a Guerra do Contestado e a modernização do Exército brasileiro na Primeira República. 2008. 430f. Tese (Doutorado em História) - Programa de Pós-Graduação em História, Universidade Federal do Rio de Janeiro, Rio de Janeiro, 2008.

SINGER, Paul. O Brasil no Contexto do capitalismo internacional: 1989-1930. In: HOLANDA, Sérgio Buarque de (Org.). História Geral da Civilização Brasileira - Tomo III: O Brasil Republicano - $1^{\circ}$ Volume: Estrutura de poder e economia (19891930). São Paulo: DIFEL, 1985. p. 345-390.

SOARES, José Octaviano Pinto. O Contestado. Subsídios para a história (1914-1915). Santa Maria: Papelaria Ângelus, [s. d.] v. II.
SOARES, José Octaviano Pinto. . O. Pinto. Subsídios para a história - o Contestado. Porto Alegre: Oficinas gráficas da Escola de Engenharia de Porto Alegre, 1920. v. I.

SOARES, José Octaviano Pinto. J. O. Pinto. Guerra em Sertões Brasileiros. Rio de Janeiro: Papelaria Velho, 1931.

THOMÉ, Nilson. A insurreição xucra do Contestado. Caçador: Fearpe, 1987.

THOMÉ, Nilson. Sangue, suor e lágrimas no chão Contestado. Caçador: Incon Edições/UNC, 1992.

THOMÉ, Nilson. A Nacionalização no Contestado, Centro-Oeste de Santa Catarina, na Primeira Metade do Século XX. Linhas, Florianópolis, v. 8, n. 1, p. 74-98, jan./ jun. - 98, jan. / jun. 2007.

THOMPSON, Edward Palmer. A miséria da teoria ou um planetário de erros - uma crítica ao pensamento de Althusser. Rio de Janeiro: Zahar, 1981.

TOMPOROSKI, Alexandre Assis. Do antes ao depois: A influência da Lumber Company para a deflagração do Movimento Sertanejo do Contestado e seu impacto na região fronteiriça entre Paraná e Santa Catarina. Revista Esboços, Florianópolis, v. 19, n. 28 , p. 68-87, dez. 2012.

TOTA, Antônio Pedro. Contestado: a guerra do novo mundo. São Paulo: Brasiliense, 1983.

VALENTINI, Delmir José. Da Cidade Santa à Corte Celeste: Memórias de sertanejos e a Guerra do Contestado. Caçador: Universidade do Contestado, 1998.

VIANNA, Celso. A batalha do Irani: o diabo na rua, no meio do redemoinho. 2002. 121 f. Dissertação (Mestrado em Antropologia) - Programa de PósGraduação em Antropologia Social, Universidade de São Paulo, São Paulo, 2002.

VINHAS DE QUEIROZ, Maurício. Messianismo e conflito social (a guerra sertaneja do Contestado - 1912-1916). Rio de Janeiro: Civilização Brasileira, 1966. 